\title{
OCS photolytic isotope effects from first principles: sulfur and carbon isotopes, temperature dependence and implications for the stratosphere
}

\author{
J. A. Schmidt ${ }^{1}$, M. S. Johnson ${ }^{1}$, S. Hattori ${ }^{2,3}$, N. Yoshida ${ }^{2,3}$, S. Nanbu ${ }^{4}$, and R. Schinke ${ }^{5}$ \\ ${ }^{1}$ Department of Chemistry, University of Copenhagen, Universitetsparken 5, 2100 Copenhagen $\varnothing$, Denmark \\ ${ }^{2}$ Department of Environmental Science and Technology, Interdisciplinary Graduate School of Science and Engineering, \\ Tokyo Institute of Technology, Yokohama, 226-8502, Japan \\ ${ }^{3}$ Department of Environmental Chemistry and Engineering, Interdisciplinary Graduate School of Science and Engineering, \\ Tokyo Institute of Technology, Yokohama, 226-8502, Japan \\ ${ }^{4}$ Faculty of Science and Technology, Sophia University, 7-1 Kioi-Cho, Chiyoda-ku, Tokyo 102-8554, Japan \\ ${ }^{5}$ Max-Planck-Institut für Dynamik und Selbstorganisation, 37073 Göttingen, Germany \\ Correspondence to: J. A. Schmidt (johanalbrechtschmidt@gmail.com)
}

Received: 10 July 2012 - Published in Atmos. Chem. Phys. Discuss.: 25 September 2012

Revised: 18 January 2013 - Accepted: 21 January 2013 - Published: 6 February 2013

\begin{abstract}
The isotopic fractionation in OCS photolysis is studied theoretically from first principles. UV absorption cross sections for OCS, $\mathrm{OC}^{33} \mathrm{~S}, \mathrm{OC}^{34} \mathrm{~S}, \mathrm{OC}^{36} \mathrm{~S}$ and $\mathrm{O}^{13} \mathrm{CS}$ are calculated using the time-depedent quantum mechanical formalism and a recently developed ab-initio description of the photodissociation of OCS which takes into account the lowest four singlet and lowest four triplet electronic states. The calculated isotopic fractionations as a function of wavelength are in good agreement with recent measurements by Hattori et al. (2011) and indicate that photolysis leads to only a small enrichment of ${ }^{34} \mathrm{~S}$ in the remaining OCS. The photodissociation dynamics provide strong evidence that the photolysis quantum yield is unity at all wavelengths for atmospheric UV excitation, for all isotopologues. A simple stratospheric model is constructed taking into account the main sink reactions of OCS and it is found that overall stratospheric removal slightly favors light OCS in constrast to the findings of Leung et al. (2002). These results show, based on isotopic considerations, that OCS is an acceptable source of background stratosperic sulfate aerosol in agreement with a recent model study of Brühl et al. (2012). The ${ }^{13} \mathrm{C}$ isotopic fractionation due to photolysis of OCS in the upper stratosphere is significant and will leave a clear signal in the remaining OCS making it a candidate for tracing using the ACE-FTS and MIPAS data sets.
\end{abstract}

\section{Introduction}

Carbonyl sulfide (OCS or COS) is an important trace gas and the most abundant sulfur compound in Earth's atmosphere (Montzka et al., 2007). The mixing ratio of OCS is about 500 ppt (parts-per-trillion i.e. pmol mol ${ }^{-1}$ ) and almost constant throughout the troposphere, and decreases rapidly with altitude in the stratosphere (Chin and Davis, 1995; Notholt et al., 2003; Barkley et al., 2008).

The sources of OCS include emission from the ocean, wetlands, soil and precipitation. The precipitation source was suggested on the basis of observations of rain water supersaturated with OCS. This source is believed to operate via chemical processes inside the rain drop (Belviso et al., 1967; Watts, 2000). Other sources of OCS are biomass burning, a variety of anthropogenic activities, volcanoes, and oxidation of carbon disulfide and dimethyl sulfide (Watts, 2000; Montzka et al., 2007).

The main sinks of OCS are uptake by vegetation and soils. OCS is relatively resistant to atmospheric oxidation, but the reactions with $\mathrm{OH}$ and ground state $\mathrm{O}$ are important in situ sinks. Photolysis is an important stratospheric sink of OCS (Watts, 2000).

OCS has an atmospheric lifetime of about two years (Montzka et al., 2007; Brühl et al., 2012) which allows it to be transported into the stratosphere where the lifetime is 
longer; Chin and Davis (1995) estimated it to be about $10 \mathrm{yr}$ while Barkley et al. (2008) found it to be $64 \pm 21 \mathrm{yr}$. The atmospheric sink reactions give products that react further and eventually form sulfur dioxide $\left(\mathrm{SO}_{2}\right)$. OCS is therefore a significant source of stratospheric $\mathrm{SO}_{2}$ which is further oxidized to sulfate. Crutzen (1976) identified OCS photolysis as a significant (non volcanic) source of material to the stratospheric sulfate aerosol (SSA) layer. This layer is important because it can enhance stratospheric ozone depletion (Solomon et al., 1993) and influence Earth's radiative balance (Turco et al., 1980; Myhre et al., 2004).

There is an ongoing debate concerning the concentration, sources and trends for the background (non-volcanic) sulfate aerosol layer. Hofmann (1990) found an increase in background SSA of 5\% per year from 1979 to 1990 at northern mid-latitudes. The background concentration of sulfate aerosol is consistently variable (Solomon et al., 2011). Given its important impact on the ozone layer and climate it is unfortunate that the sources of sulfate aerosol are not better characterized. Chin and Davis (1995) constructed a onedimensional photochemical model of the stratosphere and found that OCS could explain between $20 \%$ and $50 \%$ of background production of SSA. A later study by Pitari et al. (2002) found it to be $43 \%$. Engel and Schmidt (1994) found that most background SSA was produced by stratospheric oxidation of OCS. In contrast, Leung et al. (2002) concluded that either OCS is a minor contributor to SSA or that the current understanding of the ${ }^{34} \mathrm{~S}$ abundance in SSA and atmospheric circulation are seriously flawed. The very recent study by Brühl et al. (2012) found evidence that OCS plays a controlling role in the production of background SSA but was not able to give a quantitative figure, althought they found that the OCS to SSA conversion rate is about $0.035 \mathrm{Mt} \mathrm{S} \mathrm{yr}^{-1}$ in good agreement with the results of Chin and Davis (1995).

In a series of papers we have used stable isotope analysis to trace the stratospheric sulfur cycle (Hattori et al., 2011, 2012; Schmidt et al., 2012a). Many physical and chemical processes fractionate stable isotopes and isotopic analysis is used to trace the sources, sinks and transformations of atmospheric trace gases, cf. Johnson et al. (2002). A compound's sources and sinks are linked via the mass balance equation. Newman et al. (1991) estimated that tropospheric OCS carries a small enrichment in ${ }^{34} \mathrm{~S}\left({ }^{34} \mathrm{~S}=11 \%\right.$ ) . Castleman et al. (1974) measured an even smaller ${ }^{34} \mathrm{~S}$ enrichment in SSA $\left(\delta^{34} \mathrm{~S}=2.6 \%\right.$ ). These enrichments were reported relative to standard meteoritic sulfur $\left({ }^{32} \mathrm{~S} /{ }^{34} \mathrm{~S}=22.210\right)$. Leung et al. (2002) retrieved $O^{32} \mathrm{~S}$ and $\mathrm{OC}^{34} \mathrm{~S}$ concentrations as a function of altitude from data acquired using the NASA Jet Propulsion Laboratory MkIV Fourier Transform Infra-Red (FTIR) Spectrometer. The concentration profiles showed a very large ${ }^{34} \mathrm{~S}$ depletion in the stratosphere (down to $-400 \%$ o and highly variable). Based on this finding and the small observed ${ }^{34} \mathrm{~S}$ depletion in SSA relative to tropospheric OCS, it was concluded that OCS is not a significant source of SSA. A later study by the same group found OCS photolysis in the first UV-band gives a large ${ }^{34} \mathrm{~S}$ depletion in the remaining OCS (Colussi et al., 2004). The latter result is contradicted by the recent experimental results of Hattori et al. (2011) and Lin et al. (2011) which found that OCS photolysis produces only very small depletion or even enrichment of ${ }^{34} \mathrm{~S}$ in the remaining pool of OCS.

There have only been a few theoretical studies of the OCS photolysis isotope effects. Jørgensen et al. (2008) used the potential energy surfaces of Suzuki et al. (1998) and found that ${ }^{34} \mathrm{~S}$ enrichment is very small. A similar result was obtained by Danielache et al. (2009) using different potential energy surfaces. The latter study also considered ${ }^{13} \mathrm{C}$ fractionation and found photolysis to greately deplete OCS in ${ }^{13} \mathrm{C}$ which contradicts recent experimental results of Hattori et al. (2011).

In this study we: (I) calculate the OCS, $\mathrm{OC}^{33} \mathrm{~S}, \mathrm{OC}^{34} \mathrm{~S}$, $\mathrm{OC}^{36} \mathrm{~S}$ and $\mathrm{O}^{13} \mathrm{CS}$ absorption cross sections and derive isotopic fractionation factors at different temperatures. (II) Determine the potential for non-mass-dependent fractionation and (III) determine an overall ${ }^{34} \mathrm{~S}$ isotopic fractionation constant for the stratosphere by also considering isotopic fractionation in the atomic oxygen and hydroxyl radical sink reactions (Hattori et al., 2012; Schmidt et al., 2012a).

\section{Methodology}

The absorption cross section is a central quantity in photochemistry. It can be calculated from first principles by first constructing potential energy surfaces for the relevant electronic states (by solving the electronic Schrödinger equation) and then solving the time-dependent Schrödinger equation for the nuclear motion on the surfaces (Schinke, 1993, Chap. 4). This procedure was used by Schmidt et al. $(2009,2011)$ to describe isotopic fractionation in $\mathrm{HCl}$ and $\mathrm{N}_{2} \mathrm{O}$ photolysis. OCS photodissociation is a multi-state process involving both singlet and triplet states (Schmidt et al., 2012b,c). In what follows, the electronic states $1{ }^{1} A^{\prime}, 2{ }^{1} A^{\prime}, 1{ }^{1} A^{\prime \prime}$, and $2^{1} A^{\prime \prime}$ will be termed $\mathrm{X}, \mathrm{A}, \mathrm{B}$, and $\mathrm{C}$, respectively, and the triplet states $1^{3} A^{\prime}, 1^{3} A^{\prime \prime}, 2^{3} A^{\prime \prime}$, and $2^{3} A^{\prime}$ will be referred to as a, b, c, and d.

\subsection{Potential energy surfaces}

The potential energy surfaces (PES) for the lowest four singlet states and lowest four triplet states were calculated using the multi-configuration reference internally contracted configuration interaction (MRCI) theory (Werner and Knowles, 1988; Knowles and Werner, 1988) based on wave functions obtained by state-averaged full-valence complete active space self consistent field (CASSCF) calculations (Werner and Knowles, 1985; Knowles and Werner, 1985). The 7 core orbitals were kept frozen during the MRCI calculations. The augmented correlation consistent polarized valence quadruple zeta (aug-cc-pVQZ) basis set of Dunning Jr. (1989) was 
employed. The Davidson correction was applied in order to approximately account for contributions of higher excitations and for size-extensive energies (Langhoff and Davidson, 1974). The PESs were calculated as functions of the Jacobi coordinates $R$ (distance from $\mathrm{S}$ to the center of mass of $\mathrm{CO}$ ), $r$ (CO bond length), and $\gamma$ (angle between $\mathbf{R}$ and $\mathbf{r}$ ). For isotopomers including different carbon isotopes a coordinate transformation between the different sets of Jacobi coordinates is necessary. New transition dipole moment (TDM) functions for transitions between the ground state and excited singlet states were recently calculated at the same level of theory but with the aug-cc-pVTZ-d basis set (McBane et al., 2013). The new TDMs are significantly different from the old TDMs presented in Schmidt et al. (2012b,c) but the two sets of TDMs produce almost identical total cross sections. The new TDMs (unlike the old ones) are consistent with experimentally observed angular distributions, see McBane et al. (2013) for further details. The TDMs connecting the singlet ground state to the triplet states were calculated as functions of $\gamma$ only (Schmidt et al., 2012b,c).

These PESs and TDMs are currently the most accurate $a b$ initio surfaces available for OCS. They are the first set of surfaces to succesfully describe the first UV absorption band of carbonyl sulfide including the superimposed structure near the peak of the band, and the weak structure observed at longer wavelengths at the onset of the band (Schmidt et al., 2012b,c; McBane et al., 2013).

\subsection{Quantum mechanical calculations}

The absorption cross sections for $\mathrm{OCS}, \mathrm{OC}^{33} \mathrm{~S}, \mathrm{OC}^{34} \mathrm{~S}$, $\mathrm{OC}^{36} \mathrm{~S}$ and $\mathrm{O}^{13} \mathrm{CS}$ were calculated using the time-dependent approach (Schinke, 1993), i.e. by propagating a quantum mechanical wave packet $\Phi(t)$ and Fourier transforming the resulting autocorrelation function $S(t)=\langle\Phi(0) \mid \Phi(t)\rangle$. The wave packets at $t=0$ were defined as the product of the modulus of the TDM and a vibrational wave function of the $\mathrm{X}$ state. The six lowest vibrational states were included in the analysis. The temperature dependent cross section for excitation from the electronic ground state into a particular excited electronic state was obtained by Boltzmann averaging over all initial vibrational states including a $\left(v_{2}+1\right)$ pseudo degeneracy factor. Finally, summation of the cross sections for states A, B, C, a, b, c, and d yielded the total cross section for a given temperature $T$.

The details of the calculations and the methodology are almost identical to those given by Schmidt et al. (2012c). The only difference is the grid parameters: In this study the wave packets were represented on a three-dimensional grid with 250 points for $3 a_{0} \leq R \leq 10 a_{0}, 70$ points for $1.6 a_{0} \leq r \leq$ $3.6 a_{0}$, and 200 points for $0 \leq \gamma \leq \pi$.

Note that the experimental fractionation constants shown in this study were averaged using a moving Gaussian with full width at half maximum of $200 \mathrm{~cm}^{-1}$ (approximately $1 \mathrm{~nm})$. This damped the noise induced by oscillations at longer and shorter wavelenghts. The theoretical results were averaged using the same procedure.

\subsection{Photochemical calculations}

The rate of photolysis, $j$, under different experimental conditions or at different altitudes in the atmosphere can be calculated from the following integral,

$j=\int \mathrm{d} \lambda \sigma(\lambda) F(\lambda) \phi(\lambda)$

where $F(\lambda)$ is the quantity of light available for photolysis at given wavelength, e.g. the actinic flux in the case of atmospheric photolysis. Actinic flux data at $0.01 \mathrm{~nm}$ resolution at various altitudes were obtained from McLinden et al. (2002). The quantum yield for dissociation, $\phi(\lambda)$, is set to unity which is justified by the calculations because: $(i)$ excitation of the A and the B state (which give the main contributions to the cross section) facilitates very rapid dissociation (the dissociation lifetime is less than $100 \mathrm{fs}$ ) and the quantum yield is therefore unity for these states. This is also supported by experimental observations by Zhao et al. (1995) who found the dissociation yield to be unity at $248 \mathrm{~nm}$ (where only the A and $\mathrm{B}$ state contribute). (ii) predissociation from the $\mathrm{C}$ and c states (which is responsible for the superimposed structure in the cross section) is relatively fast. Our preliminary study of the $\mathrm{c}$ state predissociation mechanism indicates that spin-orbit interaction with the A state gives the $\mathrm{c}$ state a lifetime on the order of $\sim 0.3 \mathrm{ps}$, which is much shorter than the florescence lifetime and the collisional lifetime in the atmosphere. The $\mathrm{C}$ state couples non-adiabatically via the kinetic energy operator with the B state (forming an avoided crossing around linearity); this type of coupling is typically stronger than spin-orbit coupling and as a result the lifetime of the $\mathrm{C}$ state is likely even less than the $\mathrm{c}$ state lifetime.

\subsection{Isotopic fractionation}

The enrichment of a given isotope, e.g. ${ }^{34} \mathrm{~S}$, is quantified in terms of the relative isotope ratio difference (or isotope delta) defined as,

$\delta^{34} \mathrm{~S}=\frac{{ }^{34} R}{{ }^{34} R_{\text {ref }}}-1$,

where ${ }^{34} R_{\text {ref }}$ is the ${ }^{34} \mathrm{~S}:{ }^{32} \mathrm{~S}$ ratio in a reference, with Vienna Canyon Diablo Troilite (VCDT) being the accepted reference for sulfur. A relative isotope ratio difference for carbon$13\left(\delta^{13} \mathrm{C}\right)$ is defined in a similar way with Vienna Pee Dee Belemnite (VPDB) being the recommend reference.

We will follow the same approach in defining isotopic parameters as in the preceeding studies by Danielache et al. (2009) and Hattori et al. (2011). The $\mathrm{OC}^{34} \mathrm{~S}$ isotopic fractionation as function of wavelength is quantified using the 
Table 1. Vibrational excitation energies given in $\mathrm{cm}^{-1}$ for the different isotopologues, with $E_{i}^{\prime}=E_{i}-E_{(0,0,0)}$. The numbers in parenthesis are $E_{i}^{\prime}$ (calc) $-E_{i}^{\prime}$ (obs) with observed values taken from Belafhal et al. (1995) and Zuniga et al. (2000). ZPE is the calculated zero point vibrational energy.

\begin{tabular}{lccccc}
\hline & $\mathrm{OCS}$ & $\mathrm{OC}^{33} \mathrm{~S}$ & $\mathrm{OC}^{34} \mathrm{~S}$ & $\mathrm{OC}^{36} \mathrm{~S}$ & $\mathrm{O}^{13} \mathrm{CS}$ \\
\hline $\mathrm{ZPE}$ & 1977.9 & 1974.3 & 1970.9 & 1964.7 & 1933.2 \\
$E_{(0,0,0)}^{\prime}$ & 0.0 & 0.0 & 0.0 & 0.0 & 0.0 \\
$E_{(0,1,0)}^{\prime}$ & $516.1(-4.4)^{\mathrm{a}}$ & 515.7 & 515.3 & 514.6 & 500.8 \\
$E_{(1,0,0)}^{\prime}$ & $852.7(-6.3)^{\mathrm{b}}$ & 847.0 & $841.5(-6.2)^{\mathrm{b}}$ & 831.5 & $848.2(-6.2)^{\mathrm{b}}$ \\
$E_{(0,2,0)}^{\prime}$ & $1038.2(-8.8)^{\mathrm{b}}$ & 1037.3 & $1036.4(-8.8)^{\mathrm{b}}$ & 1034.7 & $1007.7(-8.5)^{\mathrm{b}}$ \\
$E_{(1,1,0)}^{\prime}$ & $1361.8(-10.6)^{\mathrm{a}}$ & 1355.9 & 1350.2 & 1339.7 & 1342.1 \\
$E_{(0,3,0)}^{\prime}$ & $1560.3(-13.1)^{\mathrm{a}}$ & 1558.8 & 1557.3 & 1554.8 & 1514.4 \\
$E_{(2,0,0)}^{\prime}$ & $1698.4(-12.6)^{\mathrm{b}}$ & 1687.1 & $1676.3(-12.4)^{\mathrm{b}}$ & 1656.4 & $1689.3(-12.5)^{\mathrm{b}}$ \\
$E_{(1,2,0)}^{\prime}$ & $1877.4(-14.9)^{\mathrm{b}}$ & 1870.9 & $1864.9(-14.8)^{\mathrm{b}}$ & 1853.6 & $1842.5(-14.5)^{\mathrm{b}}$ \\
$E_{(0,0,1)}^{\prime}$ & $2050.8(-11.4)^{\mathrm{b}}$ & 2050.4 & $2050.0(-11.4)^{\mathrm{b}}$ & 2049.4 & $1997.9(-11.3)^{\mathrm{b}}$ \\
$E_{(0,4,0)}^{\prime}$ & $2087.7(-17.1)^{\mathrm{b}}$ & 2085.6 & $2083.6(-17.0)^{\mathrm{b}}$ & 2079.9 & $2026.8(-16.3)^{\mathrm{b}}$ \\
\hline
\end{tabular}

${ }^{a}$ Belafhal et al. (1995)

b Zuniga et al. (2000)

fractionation constant,

${ }^{34} \epsilon(\lambda)=\frac{{ }^{34} \sigma(\lambda)}{\sigma(\lambda)}-1$,

where $\sigma(\lambda)$ and ${ }^{34} \sigma(\lambda)$ are the $\mathrm{OC}^{32} \mathrm{~S}$ and $\mathrm{OC}^{34} \mathrm{~S}$ cross sections respectively, and analogous definitions apply for the other isotopes. The effective fractionation constant can also be defined for specific photolysis conditions using,

${ }^{34} \epsilon=\frac{{ }^{34} j}{j}-1$.

Following Ueno et al. (2009) and Hattori et al. (2011) we also introduce the quantities ${ }^{33} E$ and ${ }^{36} E$ for describing departures from mass-dependent fractionation,

${ }^{i} E={ }^{i} \epsilon+1-\left({ }^{34} \epsilon+1\right){ }^{\beta_{i}}$,

with $i=33$ or $36, \beta_{33}=0.515$ and $\beta_{36}=1.90$.

\section{Results and comparison with experiments}

Table 1 lists calculated vibrational energies and deviations from experimental results for 5 different isotopologues. The absolute deviation between theory and experiment is small; the vibrational energies deviate from experimental values by at most $0.9 \%$. Furthermore, the deviation is roughly the same for all isotopologues i.e., the shift in energy with isotopic substitution is very well reproduced.

The calculated cross section for the most abundant OCS isotopologue is shown in Fig. 1 and compared with the lowtemperature experimental cross section of Robert Wu et al. (1999). Note that when summing over all the seven excited

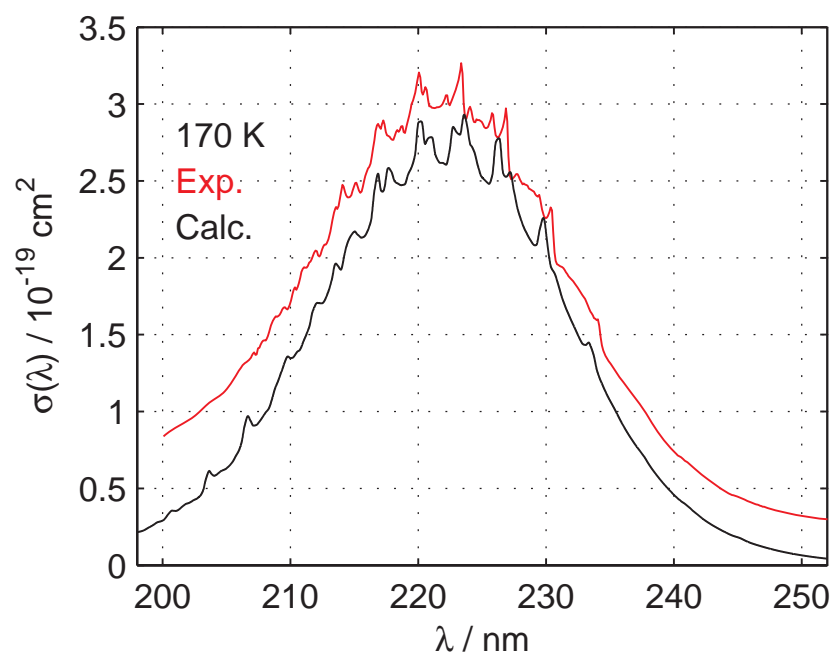

Fig. 1. The total absorption cross section (scaled by a factor of 1.3) compared with the experimental cross section of Robert $\mathrm{Wu}$ et al. (1999). The temperature in the calculation and measurement is $170 \mathrm{~K}$. The experimental cross section was shifted up by 0.25 for clarity.

electronic states the A-state cross sections for all initial states $\left(v_{1}, v_{2}, v_{3}\right)$ were shifted by $200 \mathrm{~cm}^{-1}$ to higher energies; all the other cross sections remained unshifted. This shift is less than $0.5 \%$ of the transition energy and is mainly due to computational error in the relative placement of the A-state surface. This shift was also applied in our previous theoretical studies (Schmidt et al., 2012b,c). The magnitude of the shift was determined by comparison to experimental cross sections, and the calculations are therefore not strictly ab-initio. Probably due to inaccuracies of the TDMs, the calculated 

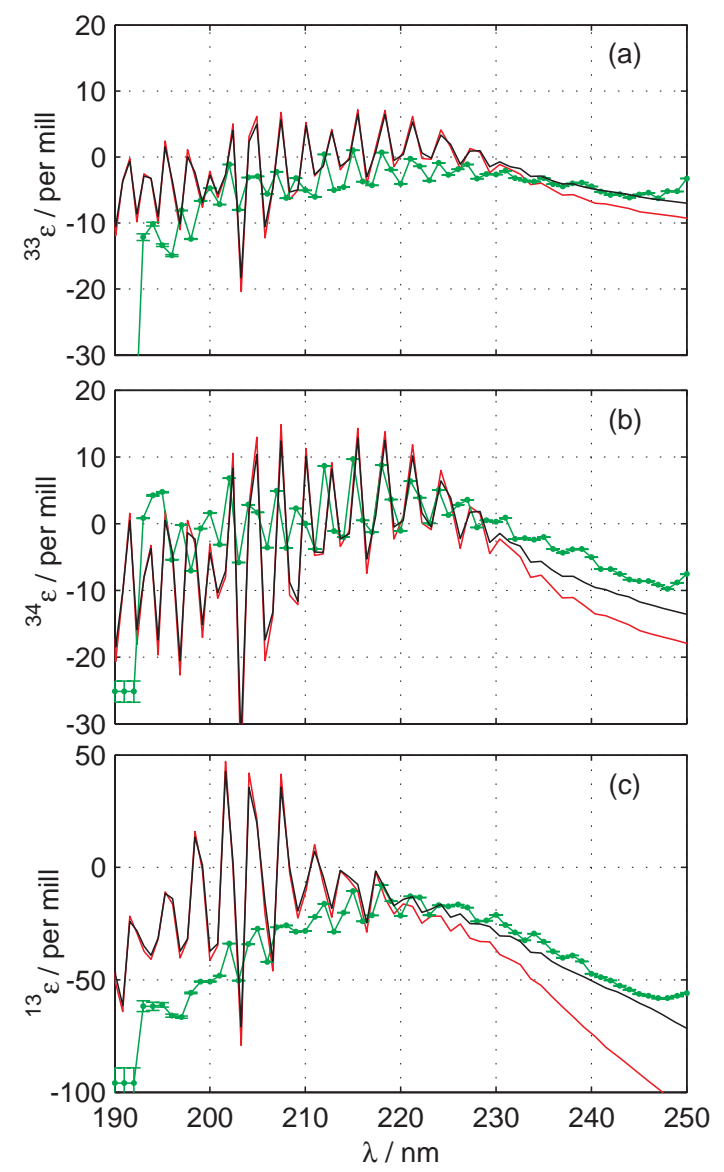

Fig. 2. (a) The calculated ${ }^{33} \mathrm{~S}$ fractionation constant vs. wavelength at $295 \mathrm{~K}$ (black) and $220 \mathrm{~K}$ (red) compared to the experimental ${ }^{33} \mathrm{~S}$ fractionation constant at room temperature (green) by Hattori et al. (2011). (b) ${ }^{34} \mathrm{~S}$ fractionation constant. (c) ${ }^{13} \mathrm{C}$ fractionation constant.

cross section is about $30 \%$ smaller than the measured one and therefore it was multiplied by 1.3 in Fig. 1; a similar deviation was observed for $\mathrm{N}_{2} \mathrm{O}$ (Schinke et al., 2010; Schinke, 2011). Overall, the theoretical and experimental cross sections are in good agreement including the width of the broad continuum and the positions and intensities of the superimposed structures.

\subsection{Photolytic isotope effects}

Figure 2 shows the theoretical fractionation constants compared with the experimental results of Hattori et al. (2011). The experimental data of Hattori et al. (2011) were recorded with a spectral resolution of $0.1 \mathrm{~nm}$ and in intervals of $0.02 \mathrm{~nm}$ while the theoretical data was calculated in intervals of $1 \mathrm{~cm}^{-1}$ (approximately $0.01 \mathrm{~nm}$ ). To ease comparison, the resolution of both the experimental and the theorectical cross sections were degraded by applying a moving Gaussian average with FWHM of $200 \mathrm{~cm}^{-1}$. This averaged out the noise in the experimental cross sections at $\lambda>240 \mathrm{~nm}$ and $\lambda<$
$210 \mathrm{~nm}$. Overall, the agreement between experiment and theory is excellent. The theoretical fractionation constants tend to be more structured at shorter wavelengths than observed in the experiment. The theoretical cross section (Fig. 1) also shows slightly too much structure on the high energy side. The sulfur isotope fractionation is small in the stratospheric UV window $(\sim 190-220 \mathrm{~nm})$ but becomes more negative at longer wavelengths. The position, intensity and frequency of structure in the calculations agree well with experimental results. The ${ }^{13} \mathrm{C}$ fractionation constant $\left({ }^{13} \epsilon\right)$ is more negative than ${ }^{34} \epsilon$, reflecting the larger relative change in mass. Furthermore isotopic substitution of the central $\mathrm{C}$ atom has a larger effect on the bending degree of freedom (see Table 1) and the vibrational wavefunction of $\mathrm{O}^{13} \mathrm{CS}$ becomes more localized around $\gamma=0^{\circ}$ (i.e. linear geometry) where the TDM is small thus lowering the overall cross section. The largest deviation between the experimental and theoretical fractionation constants is seen for ${ }^{13} \epsilon$ in the high energy region (190 to $205 \mathrm{~nm}$ ). This deviation could be due to an overestimation of the TDM around linear geometry; a smaller TDM around $\gamma=0^{\circ}$ would amplify the isotope effect on the high energy side. Alternatively, the deviation could be the result of an isotope dependent intrusion of the second UV band of OCS. This band rises rapidly beyond $<190 \mathrm{~nm}$, it is more structured and peaks at around $168 \mathrm{~nm}$, and its low energy tail likely gives a (small) contribution to the spectrum in the 190 to $200 \mathrm{~nm}$ range (McGlynn et al., 1971). Such a contribution is not captured in the calculations (which do not consider the second UV band). Finally the deviation seen for ${ }^{13} \epsilon$ in the high energy region could be due to experimental error.

For direct dissociation, where the absorption cross section is characterized by a broad continuum, substitution with a heavier isotope tends to make the cross section more narrow (due to a narrowing of the vibrational wavefunction, cf. Liang et al., 2004) and shift the cross section to higher energies (due a lowering of the vibrational zero point energy, cf. Yung and Miller, 1997). The change in the cross section with isotopic substitution is marginal near the center while it is significant on the shoulders. In particular, the cross sections for the heavy isotope tends to be smaller on the low energy side due to the narrowing of the ground state vibrational wave functions and lowering of the ground state vibrational energies. Stratospheric photolysis of OCS occurs near the center of the cross section where the fractionation constant is close to zero. In contrast, $\mathrm{N}_{2} \mathrm{O}$ photolysis occurs on the low energy shoulder of the cross section giving rise to a large enrichment of heavy $\mathrm{N}_{2} \mathrm{O}$ in the stratosphere (Kim and Craig, 1993; Rahn and Wahlen, 1997; Toyoda et al., 2001; Röckmann et al., 2001; Prakash et al., 2005; Chen et al., 2008, 2010).

Since the vibrational wavefunctions of the heavy isotopologues of OCS tend to be more localized around linearity (i.e. more narrow) the cross sections for these isotopologues will be smaller than that of light OCS at long wavelengths. A similar effect is seen in $\mathrm{N}_{2} \mathrm{O}$ (Johnson et al., 2001). The 

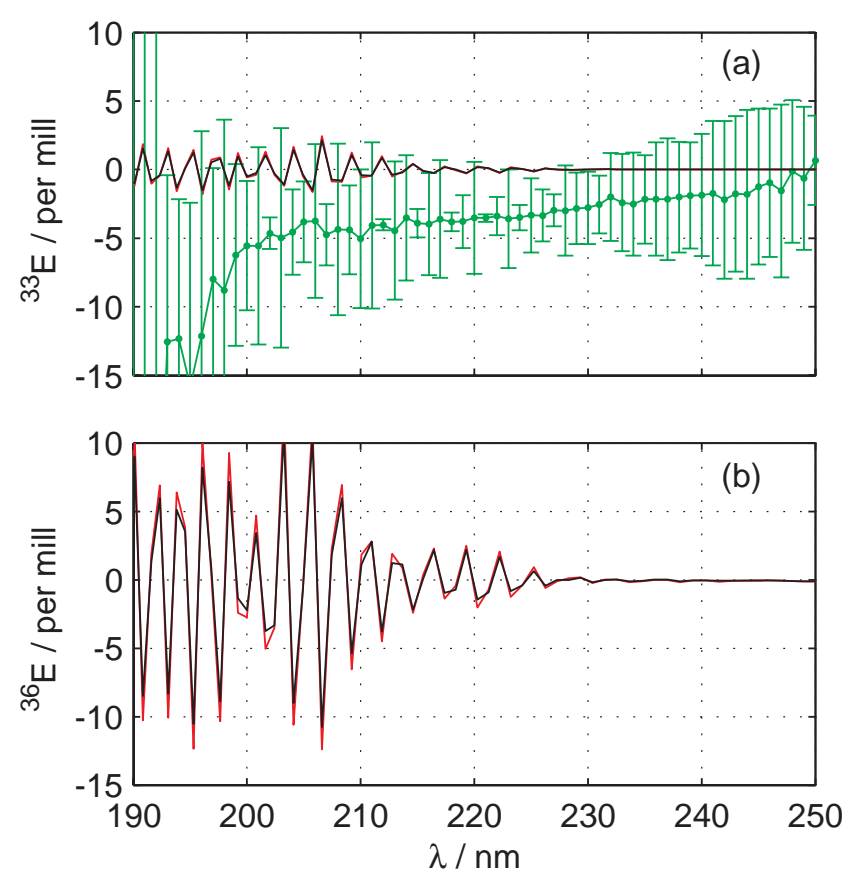

Fig. 3. (a) The calculated ${ }^{33} E$ vs. wavelength at $295 \mathrm{~K}$ (black) and $220 \mathrm{~K}$ (red) compared to the experimental results at room temperature (green) by Hattori et al. (2011). (b) The calculated ${ }^{36} E$ vs. wavelength at $295 \mathrm{~K}$ (black) and $220 \mathrm{~K}$ (red).

smaller cross section leads to a negative fractionation constant at long wavelengths. This contradicts the findings of Colussi et al. (2004) who reported very large and positive ${ }^{34} \mathrm{~S}$ fractionation constant; between $+25 \%$ and $+150 \%$ in the 250 to $200 \mathrm{~nm}$ range.

Figure 3 shows the calculated ${ }^{33} E$ and ${ }^{36} E$ compared to the experimental results of Hattori et al. (2011). The calculated ${ }^{33} E$ is very close to $0 \%$ and shows marginal structure while the experimental ${ }^{33} E$ is zero at long wavelengths but shows a negative trend with decreasing wavelength; however, theory and experiment generally agree to within the experimental uncertainty. The calculated ${ }^{36} E$ is shown in Fig. 3b; note that no wavelength resolved experimental data are available for ${ }^{36} E$. Both ${ }^{33} E$ and ${ }^{36} E$ are almost unaffected by cooling from $295 \mathrm{~K}$ to $220 \mathrm{~K}$.

\subsection{Atmospheric implications}

The OCS photolytic isotopic fractionation in the tropopause region and the stratosphere of the US standard atmosphere was calculated using the actinic flux data of McLinden et al. (Fig. 4) and the calculated cross sections together with Eq. (1) and is summarized in Fig. 5a. Above $15 \mathrm{~km}$ the ${ }^{34} \mathrm{~S}$ fractionation constant is close to zero; between 16 and $30 \mathrm{~km}$ it is slightly negative, and between 30 and $45 \mathrm{~km}$ it is slightly positive, while it becomes slightly negative again above $45 \mathrm{~km}$. The ${ }^{33} \mathrm{~S}$ and ${ }^{36} \mathrm{~S}$ fractionation constants (not shown) are qualitatively similar. The ${ }^{13} \mathrm{C}$ isotopic fraction

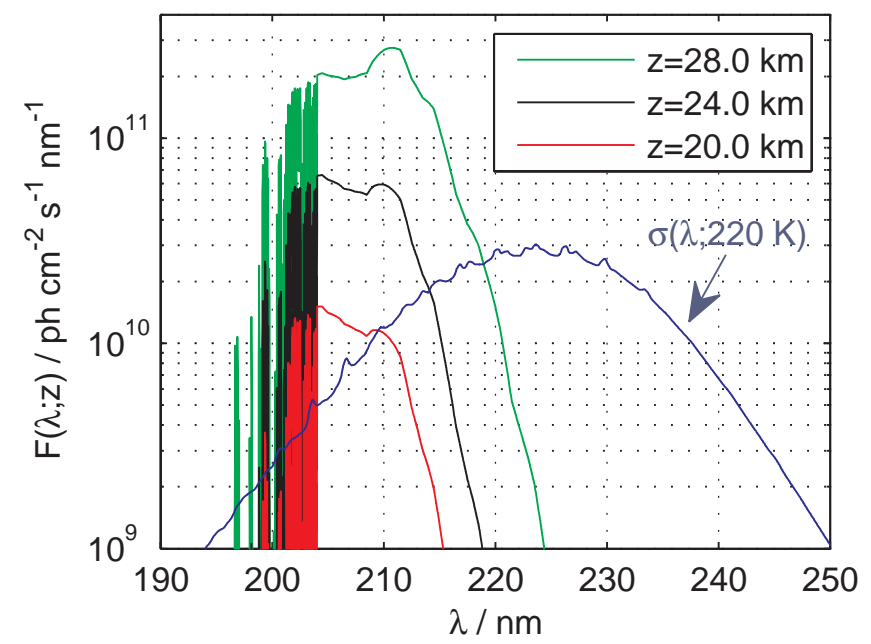

Fig. 4. The actinic flux of McLinden et al. (2002) at three different altitudes. The calculated absorption cross section for OCS at $220 \mathrm{~K}$ is also shown (multiplied by $10^{29}$ and given in units of $\mathrm{cm}^{2}$ ).

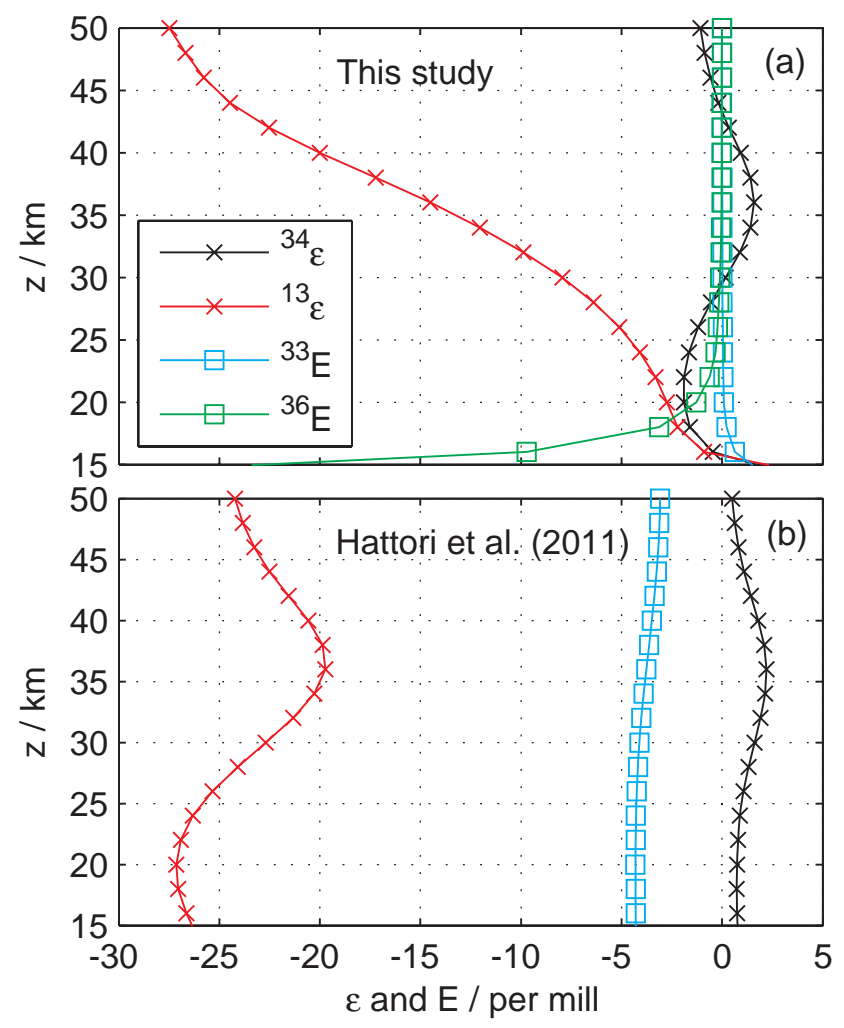

Fig. 5. (a) The photolytic fractionation constants ${ }^{34} \epsilon$ and ${ }^{13} \epsilon$, and the quantities ${ }^{33} E$ and ${ }^{36} E$ as defined in Eqs. 4 and 5 as a function of altitude calculated using the theoretical temperature dependent cross sections. The actinic flux as an a function of $z$ was taken from McLinden et al. (2002) while the temperature was modeled using the US standard atmosphere. (b) Same as (a) but using the experimental cross sections of Hattori et al. (2011) (fixed at room temperature). 
Table 2. A very simple stratospheric model. Concentrations, rate constants and fractionation constants in the upper part of the table are used to derive the total stratospheric lifetime and fraction constants in the lower part of the table. Numbers in parenthesis were calculated using the experimental cross sections of Hattori et al. (2011).

\begin{tabular}{|c|c|c|c|c|c|c|c|}
\hline & $16 \mathrm{~km}$ & $20 \mathrm{~km}$ & $24 \mathrm{~km}$ & $28 \mathrm{~km}$ & $32 \mathrm{~km}$ & $36 \mathrm{~km}$ & note \\
\hline$T / \mathrm{K}$ & 216.6 & 216.6 & 220.6 & 224.5 & 228.5 & 239.3 & (a) \\
\hline$p /$ mbar & 103.5 & 55.3 & 29.7 & 16.2 & 8.9 & 5.0 & (a) \\
\hline$n / \mathrm{cm}^{-3}$ & $3.46 \times 10^{18}$ & $1.85 \times 10^{18}$ & $0.98 \times 10^{18}$ & $0.52 \times 10^{18}$ & $0.28 \times 10^{18}$ & $0.15 \times 10^{18}$ & (a) \\
\hline$[\mathrm{OCS}] / \mathrm{ppt}$ & 310 & 180 & 110 & 100 & - & - & (b) \\
\hline$[\mathrm{O}] / \mathrm{ppt}$ & 0.3 & 1.6 & 10.2 & 38.4 & 249 & 663 & (c) \\
\hline$[\mathrm{OH}] / \mathrm{ppt}$ & 0.3 & 0.5 & 2.0 & 5.8 & 18 & 66 & (c) \\
\hline$j_{\mathrm{ph}} / \mathrm{s}^{-1}$ & $0.13 \times 10^{-8}$ & $1.1 \times 10^{-8}$ & $6.0 \times 10^{-8}$ & $32.6 \times 10^{-8}$ & $155 \times 10^{-8}$ & $558 \times 10^{-8}$ & (d) \\
\hline$k_{\mathrm{O}} / \mathrm{cm}^{3} \mathrm{~s}^{-1}$ & $8.15 \times 10^{-16}$ & $8.15 \times 10^{-16}$ & $9.80 \times 10^{-16}$ & $11.7 \times 10^{-16}$ & $13.8 \times 10^{-16}$ & $21.4 \times 10^{-16}$ & (c) \\
\hline$k_{\mathrm{OH}} / \mathrm{cm}^{3} \mathrm{~s}^{-1}$ & $5.51 \times 10^{-18}$ & $4.40 \times 10^{-18}$ & $4.45 \times 10^{-18}$ & $4.66 \times 10^{-18}$ & $5.14 \times 10^{-18}$ & $8.58 \times 10^{-18}$ & (f) \\
\hline${ }^{34} \epsilon_{\mathrm{ph}} / \% o$ & $-0.5(0.7)$ & $-1.9(0.7)$ & $-1.6(0.9)$ & $-0.6(1.3)$ & $0.9(1.9)$ & $1.6(2.2)$ & (d) \\
\hline${ }^{34} \epsilon_{\mathrm{O}} / \%$ & -21.7 & -21.7 & -21.7 & -21.7 & -21.7 & -21.7 & (e) \\
\hline${ }^{34} \epsilon_{\mathrm{OH}} / \%$ o & -1.9 & -3.7 & -6.9 & -10.7 & -14.2 & -16.8 & (f) \\
\hline${ }^{13} \epsilon_{\mathrm{ph}} / \% o$ & $-0.9(-26.7)$ & $-2.7(-27.2)$ & $-4.1(-26.3)$ & $-6.4(-24.1)$ & $-9.9(-21.3)$ & $-14.4(-19.7)$ & (d) \\
\hline${ }^{13} \epsilon_{\mathrm{O}} / \%$ & -17.0 & -17.0 & -16.6 & -16.2 & -15.9 & -14.9 & (g) \\
\hline${ }^{13} \epsilon_{\mathrm{OH}} / \%$ & -47.2 & -52.1 & -60.6 & -71.7 & -82.2 & -88.1 & (f) \\
\hline$\tau / \mathrm{yr}$ & 58.1 & 9.6 & 1.8 & 0.36 & 0.08 & 0.02 & (h) \\
\hline${ }^{34} \epsilon_{\text {tot }} 1 \%$ & $-8.7(-8.0)$ & $-5.5(-3.4)$ & $-4.4(-2.3)$ & $-2.0(-0.2)$ & $-0.4(0.5)$ & $0.7(1.3)$ & (i) \\
\hline${ }^{13} \epsilon_{\text {tot }} / \%$ & $-7.3(-23.0)$ & $-5.3(-25.0)$ & $-5.9(-24.9)$ & $-7.0(-23.6)$ & $-10.2(-21.0)$ & $-14.5(-19.6)$ & (i) \\
\hline
\end{tabular}

(a) US standard atmosphere

(b) Figure 4 in Barkley et al. (2008)

(c) From JPL 2007 guide $\left(40^{\circ} \mathrm{N}\right.$, noon)

(d) This study using eq. 1 and 4 (equator at noon)

(e) Hattori et al. (2012)

(f) Schmidt et al. (2012a)

(g) Calculated, see Hattori et al. (2012) for computational details

(h) $\tau=4 \cdot r_{\mathrm{tot}}{ }^{-1}=4 \cdot\left(j_{\mathrm{ph}}+k_{\mathrm{O}}[\mathrm{O}]+k_{\mathrm{OH}}[\mathrm{OH}]\right)^{-1}$. The factor of 4 is introduced to get an approximate global day/night average of $j_{\mathrm{ph}},[\mathrm{O}]$ and $[\mathrm{OH}]$

(i) ${ }^{x} \epsilon_{\text {tot }}={ }^{x} r_{\text {tot }} / r_{\text {tot }}-1$ with $x=34$ or 13

is negative above $16 \mathrm{~km}$ and becomes increasingly negative with increasing altitude. The fractionation constants shown in Fig. 5b were calculated using the experimental cross sections of Hattori et al. (2011). Again, the ${ }^{34} \mathrm{~S}$ fractionation constant is close to zero. The carbon-13 fractionation in Fig. $5 \mathrm{~b}$ is more severe than in Fig. 5a; this deviation can be directly traced back to the deviation between experiment and theory for ${ }^{13} \epsilon$ around $200 \mathrm{~nm}$.

Figure 5a also shows ${ }^{33} E$ and ${ }^{36} E$ as function of $z$. At altitudes above $20 \mathrm{~km}^{33} E$ and ${ }^{36} E$ are both close to 0 and photolysis is mass-dependent. At altitudes below $20 \mathrm{~km}{ }^{33} E$ and ${ }^{36} E$ start to diverge in opposite directions giving nonmass-dependent fractionation. Below $20 \mathrm{~km}$ the UV window is narrow and sharp ( 205 to $212 \mathrm{~nm}$, see Fig. 4) and photodissociation primarily occurs in a narrow region on the high energy shoulder of the cross section. The narrow window creates a situation were the vibrational structure of the cross sections of the different isotopologues can lie just inside or just outside the window, "opening the door" for non-massdependent fractionation. Unfortunately the window is centered in the region where the calculated cross section is too structured compared to experiment. The very sharp cutoff of the actinic flux below $205 \mathrm{~nm}$ is due to absorption by $\mathrm{O}_{2}$.
A simple chemical box model was constructed to get an initial picture of isotopic fractionation caused by the OCS stratospheric sink reactions. The rate constant for the stratospheric removal of OCS was calculated as,

$r_{\mathrm{tot}}=j_{\mathrm{ph}}+k_{\mathrm{O}}[\mathrm{O}]+k_{\mathrm{OH}}[\mathrm{OH}]$.

Analog rate constants were calculated for $\mathrm{O}^{13} \mathrm{CS}$ and $\mathrm{OC}^{34} \mathrm{~S}$ and used to derive the carbon-13 and sulfur-34 fractionation of the stratosphere $\left({ }^{13} \epsilon_{\text {tot }}\right.$ and $\left.{ }^{34} \epsilon_{\text {tot }}\right)$. The results of the model and the input parameters are shown in Table 2 for six different altitudes. When calculating the total lifetime of OCS against the sinks $j_{\mathrm{ph}},[\mathrm{O}]$ and $[\mathrm{OH}]$ were scaled by a factor of $\frac{1}{4}$ to get a global day/night average of the photolysis rate and effective $\mathrm{O}$ and $\mathrm{OH}$ concentrations. The combined ${ }^{34} \mathrm{~S}$ fractionation of the three sink reactions is small and negative at the six altitudes. It is difficult to reconcile the total ${ }^{34} \mathrm{~S}$ fractionation constant of our study (second last line of Table 2) with the value of ${ }^{34} \epsilon=(73.8 \pm 8.6) \%$ o presented by Leung et al. (2002) for the stratosphere. The large stratospheric fractionation constant was suggested to be due to photolysis and Colussi et al. (2004) did indeed find photolysis to have a large positive fractionation constant of ${ }^{34} \epsilon=(67 \pm 7) \%$, however our results and recent studies show that the photolytic ${ }^{34} \mathrm{~S}$ 
fractionation constant in general is much smaller and negative (Hattori et al., 2011; Lin et al., 2011).

The ${ }^{13} \mathrm{C}$ fractionation in the stratosphere is also negative but has a larger magnitude, especially in the upper stratosphere. The magnitude of ${ }^{13} \epsilon$ increases with altitude. The larger isotopic fractionation for ${ }^{13} \mathrm{C}$ may produce a strong enough signal in the OCS isotopic composition to be detected using the ACE-FTS or MIPAS data sets leading to a better quantification of background SSA, which is important input to climate models (Myhre et al., 2004; Solomon et al., 2011).

\section{Conclusions}

In this study we found:

1. OCS photolytic ${ }^{34} \mathrm{~S}$ isotopic fractionation is marginal validating recent studies by Hattori et al. (2011) and Lin et al. (2011) while directly contradicting the findings of Colussi et al. (2004).

2. The overall ${ }^{34} \mathrm{~S}$ isotopic fractionation of OCS in the stratosphere is small and negative which contradicts the findings of Leung et al. (2002) and makes OCS an acceptable source of background SSA in agreement with a recent model study of Brühl et al. (2012).

3. ${ }^{13} \mathrm{C}$ fractionation of stratospheric OCS is more significant and becomes increasingly negative with altitude which may make ${ }^{13} \mathrm{C}$ a tracer candidate for the ACEFTS and MIPAS data sets.

The data allows for a detailed photochemical model á laMcLinden et al. (2003) to be constructed. However more field/remote sensing studies are needed to better quantify the isotopic composition of SSA and troposheric and stratospheric OCS.

Acknowledgements. We thank Chris McLinden for providing us with the actinic flux data. We thank the IntraMIF project in the European Community's Seventh Framework Programme (FP7/2007-1013) under grant agreement number 237890 for support. We thank the Gesellschaft für wissenschaftliche Datenverarbeitung mbH Göttingen (GWDG) for computational resources. This work is supported by Grant in Aid for Scientific Research (S) (23224013) of Ministry of Education, Culture, Sports, and Technology (MEXT), Japan. S. H. is supported by Grant in Aid for JSPS Research Fellows (DC1(No. 22-7563)) and Global COE program "From the Earth to Earths" of MEXT, Japan.

Edited by: T. Röckmann

\section{References}

Barkley, M. P., Palmer, P. I., Boone, C. D., Bernath, P. F., and Suntharalingam, P.: Global distributions of carbonyl sulfide in the upper troposphere and stratosphere, Geophys. Res. Lett., 35, L14810, doi:10.1029/2008GL034270, 2008.

Belafhal, A., Fayt, A., and Guelachvili, G.: Fourier transform spectroscopy of carbonyl sulfide from 1800 to $3120 \mathrm{~cm}^{-1}$ : the normal species, J. Mol. Struct., 174, 1-19, doi:10.1006/jmsp.1995.1264, 1995.

Belviso, S., Mihalopoulos, N., and Nguyen, B. C.: The supersaturation of carbonyl sulfide (OCS) in rain waters, Atmos. Environ., 21, 1363-1367, doi:10.1016/0004-6981(67)90083-2, 1967.

Brühl, C., Lelieveld, J., Crutzen, P. J., and Tost, H.: The role of carbonyl sulphide as a source of stratospheric sulphate aerosol and its impact on climate, Atmos. Chem. Phys., 12, 1239-1253, doi:10.5194/acp-12-1239-2012, 2012.

Castleman, A. W., Munkelwitz, H. R., and Manowitz, B.: Isotopic studies of the sulfur component of the stratospheric aerosol layer, Tellus B, 26, 222-234, available at: http://www.tellusb.net/index. php/tellusb/article/view/13739/15505, 1974.

Chen, W.-C., Prakash, M. K., and Marcus, R. A.: Isotopomer fractionation in the UV photolysis of $\mathrm{N}_{2} \mathrm{O}: 2$. Further comparison of theory and experiment, J. Geophys. Res., 113, D05309, doi:10.1029/2007JD009180, 2008.

Chen, W.-C., Nanbu, S., and Marcus, R. A.: Isotopomer fractionation in the UV photolysis of $\mathrm{N}_{2} \mathrm{O}$ : 3. 3-D ab initio surfaces and anharmonic effects, J. Phys. Chem. A, 114, 9700-9708, doi:10.1021/jp101691r, 2010.

Chin, M. and Davis, D. D.: A reanalysis of carbonyl sulfide as a source of stratospheric background sulfur aerosol, J. Geophys. Res., 100, 8993-9005, doi:10.1029/95JD00275, 1995.

Colussi, A. J., Leung, F., and Hoffmann, M. R.: Electronic spectra of carbonyl sulfide sulfur isotopologues, Environ. Chem., 1, 4448, doi:10.1071/EN04010, 2004.

Crutzen, P. J.: The possible importance of CSO for the sulfate layer of the stratosphere, Geophys. Res. Lett., 3, 73-76, doi:10.1029/GL003i002p00073, 1976.

Danielache, S. O., Nanbu, S., Eskebjerg, C., Johnson, M. S., and Yoshida, N.: Carbonyl sulfide isotopologues: ultraviolet absorption cross sections and stratospheric photolysis, J. Chem. Phys., 131, 024307, doi:10.1063/1.3156314, 2009.

Dunning Jr., T. H.: Gaussian basis sets for use in correlated molecular calculations. I. The atoms boron through neon and hydrogen, J. Chem. Phys., 90, 1007-1023, doi:10.1063/1.456153, 1989.

Engel, A. and Schmidt, U.: Vertical profile measurements of carbonylsulfide in the stratosphere, Geophys. Res. Lett., 21, 22192222, doi:10.1029/94GL01461, 1994.

Hattori, S., Danielache, S. O., Johnson, M. S., Schmidt, J. A., Kjaergaard, H. G., Toyoda, S., Ueno, Y., and Yoshida, N.: Ultraviolet absorption cross sections of carbonyl sulfide isotopologues $\mathrm{OC}^{32} \mathrm{~S}, \mathrm{OC}^{33} \mathrm{~S}, \mathrm{OC}^{34} \mathrm{~S}$ and $\mathrm{O}^{13} \mathrm{CS}$ : isotopic fractionation in photolysis and atmospheric implications, Atmos. Chem. Phys., 11, 10293-10303, doi:10.5194/acp-11-10293-2011, 2011.

Hattori, S., Schmidt, J. A., Mahler, D. W., Danielache, S. O., Johnson, M. S., and Yoshida, N.: Isotope effect in the carbonyl sulfide reaction with $\mathrm{O}\left({ }^{3} P\right)$, J. Phys. Chem. A, 116, 3521-3526, doi:10.1021/jp2120884, 2012. 
Hofmann, D. J.: Increase in the stratospheric background sulfuric acid aerosol mass in the past 10 years, Science, 248, 996-1000, doi:10.1126/science.248.4958.996, 1990.

Johnson, M. S., Billing, G. D., Gruodis, A., and Janssen, M. H. M.: Photolysis of nitrous oxide isotopomers studied by timedependent hermite propagation, J. Phys. Chem. A, 105, 86728680, doi:10.1021/jp011449x, 2001.

Johnson, M. S., Feilberg, K. L., Hessberg, P. v., and Nielsen, O. J.: Isotopic processes in atmospheric chemistry, Chem. Soc. Rev., 31, 313-323, doi:10.1039/B108011N, 2002.

Jørgensen, S., Grage, M. M.-L., Nyman, G., and Johnson, M. S.: Isotope Effects in Photodissociation: Chemical Reaction Dynamics and Implications for Atmospheres, Adv. Quantum Chem., 55, 101-135, doi:10.1016/S0065-3276(07)00207-9, 2008.

Kim, K.-R. and Craig, H.: Nitrogen-15 and oxygen-18 characteristics of nitrous oxide: a global perspective, Science, 262, 18551857, doi:10.1126/science.262.5141.1855, 1993.

Knowles, P. J. and Werner, H.-J.: An efficient second-order MC SCF method for long configuration expansions, Chem. Phys. Lett., 115, 259-267, doi:10.1016/0009-2614(85)80025-7, 1985.

Knowles, P. J. and Werner, H.-J.: An efficient method for the evaluation of coupling coefficients in configuration interaction calculations, Chem. Phys. Lett., 145, 514-522, doi:10.1016/00092614(88)87412-8, 1988.

Langhoff, S. R. and Davidson, E. R.: Configuration interaction calculations on the nitrogen molecule, J. Quantum Chem., 8, 61-72, doi:10.1002/qua.560080106, 1974.

Leung, F., Colussi, A. J., and Hoffmann, M. R.: Isotopic fractionation of carbonyl sulfide in the atmosphere: Implications for the source of background stratospheric sulfate aerosol, Geophys. Res. Lett., 29, 1474, doi:10.1029/2001GL013955, 2002.

Liang, M.-C., Blake, G. A., and Yung, Y. L.: A semianalytic model for photo-induced isotopic fractionation in simple molecules, J. Geophys. Res., 109, D10308, doi:10.1029/2004JD004539, 2004.

Lin, Y., Sim, M. S., and Ono, S.: Multiple-sulfur isotope effects during photolysis of carbonyl sulfide, Atmos. Chem. Phys., 11, 10283-10292, doi:10.5194/acp-11-10283-2011, 2011.

McBane, G. C., Schmidt, J. A., Johnson, M. S., and Schinke, R.: UV photodissociation of OCS: Product energy and angular distributions, submitted, 2013.

McGlynn, S. P., Rabalais, J. W., McDonald, J. R., and Scherr, V. M.: Electronic spectoscopy of isoelectronic molecules. II. Linear triatomic groupings containing sixteen valence electrons, Chem. Rev., 71, 73-108, doi:10.1021/cr60269a004, 1971.

McLinden, C. A., McConnell, J. C., Griffioen, E., and McElroy, C. T.: A vector radiative-transfer model for the Odin/OSIRIS project, Can. J. Phys., 80, 375-393, doi:10.1139/p01-156, 2002.

McLinden, C. A., Prather, M. J., and Johnson, M. S.: Global modeling of the isotopic analogues of $\mathrm{N}_{2} \mathrm{O}$ : Stratospheric distributions, budgets, and the ${ }^{17} \mathrm{O}-{ }^{18} \mathrm{O}$ mass-independent anomaly, J. Geophys. Res., 108, 4233, doi:10.1029/2002JD002560, 2003.

Montzka, S. A., Calvert, P., Hall, B. D., Elkins, J. W., Conway, T. J., Tans, P. P., and Sweeney, C.: On the global distribution, seasonality, and budget of atmospheric carbonyl sulfide (COS) and some similarities to $\mathrm{CO}_{2}$, J. Geophys. Res., 112, D09302, doi:10.1029/2006JD007665, 2007.

Myhre, G., Berglen, T. F., Myhre, C. E. L., and Isaksen, I. S.: The radiative effect of the anthropogenic influence on the stratospheric sulfate aerosol layer, Tellus B, 56, 294-299, doi:10.1111/j.1600- 0889.2004.00106.x, 2004.

Newman, L., Krouse, H. R., and Grinenko, V. A.: Chapter 5: Sulphur isotope variations atmosphere, in: Stable Isotopes in the Assessment of Natural and Anthropogenic Sulphur in the Environment, edited by: Krouse, H. R. and Grinenko, V. A., vol. 43 of SCOPE, John Wiley \& Sons Ltd, http://www.icsu-scope.org/ downloadpubs/scope43/index.html, 133-176, 1991.

Notholt, J., Kuang, Z., Rinsland, C. P., Toon, G. C., Rex, M., Jones, N., Albrecht, T., Deckelmann, H., Krieg, J., Weinzierl, C., Bingemer, H., Weller, R., and Schrems, O.: Enhanced upper tropical tropospheric COS: impact on the stratospheric aerosol layer, Science, 300, 307-310, doi:10.1126/science.1080320, 2003.

Pitari, G., Mancini, E., Rizi, V., and Shindell, D. T.: Impact of future climate and emission changes on stratospheric aerosols and ozone, J. Atmos. Sci., 59, 414-440, doi:10.1175/15200469(2002)059<0414:IOFCAE>2.0.CO;2, 2002.

Prakash, M. K., Weibel, J. D., and Marcus, R. A.: Isotopomer fractionation in the $\mathrm{UV}$ photolysis of $\mathrm{N}_{2} \mathrm{O}$ : comparison of theory and experiment, J. Geophys. Res., 110, D21315, doi:10.1029/2005JD006127, 2005.

Rahn, T. and Wahlen, M.: Stable isotope enrichment in stratospheric nitrous oxide, Science, 278, 1776-1778, doi:10.1126/science.278.5344.1776, 1997.

Robert Wu, C. Y., Chen, F. Z., and Judge, D. L.: Temperaturedependent photoabsorption cross sections of OCS in the 2000-2600 Å Region, J. Quant. Spectrosc. Ra., 61, 265-271, doi:10.1016/S0022-4073(97)00220-3, 1999.

Röckmann, T., Kaiser, J., Brenninkmeijer, C. A. M., Crowley, J. N., Borchers, R., Brand, W. A., and Crutzen, P. J.: Isotopic enrichment of nitrous oxide $\left({ }^{15} \mathrm{~N}^{14} \mathrm{~N}^{16} \mathrm{O},{ }^{14} \mathrm{~N}^{15} \mathrm{~N}^{16} \mathrm{O},{ }^{14} \mathrm{~N}^{14} \mathrm{~N}^{18} \mathrm{O}\right)$ in the stratosphere and in the laboratory, J. Geophys. Res., 106, 10403-10410, doi:10.1029/2000JD900822, 2001.

Schinke, R.: Photodissociation Dynamics, Cambridge University Press, New York, 1993.

Schinke, R.: Photodissociation of $\mathrm{N}_{2} \mathrm{O}$ : potential energy surfaces and absorption spectrum, J. Chem. Phys., 134, 064313, doi:10.1063/1.3553377, 2011.

Schinke, R., Suarez, J., and Farantos, S. C.: Communication: photodissociation of $\mathrm{N}_{2} \mathrm{O}$ - frustrated $\mathrm{NN}$ bond breaking causes diffuse vibrational structures, J. Chem. Phys., 133, 091103, doi:10.1063/1.3479391, 2010.

Schmidt, J., Johnson, M., Jung, Y., Danielache, S., Hattori, S., and Yoshida, N.: Predictions of the sulfur and carbon kinetic isotope effects in the $\mathrm{OH}+$ OCS reaction, Chem. Phys. Lett., 531, 6469, doi:10.1016/j.cplett.2012.02.049, 2012a.

Schmidt, J. A., Johnson, M. S., Grage, M. M.-L., and Nyman, G.: On the origin of the asymmetric shape of the $\mathrm{HCl}$ photodissociation cross section, Chem. Phys. Lett., 480, 168-172, doi:10.1016/j.cplett.2009.09.014, 2009.

Schmidt, J. A., Johnson, M. S., and Schinke, R.: Isotope effects in $\mathrm{N}_{2} \mathrm{O}$ photolysis from first principles, Atmos. Chem. Phys., 11, 8965-8975, doi:10.5194/acp-11-8965-2011, 2011.

Schmidt, J. A., Johnson, M. S., McBane, G. C., and Schinke, R.: Communication: multi-state analysis of the carbonyl sulfide ultraviolet absorption including vibrational structure, J. Chem. Phys., 136, 131101, doi:10.1063/1.3701699, 2012 b.

Schmidt, J. A., Johnson, M. S., McBane, G. C., and Schinke, R.: The ultraviolet spectrum of OCS from first principles: electronic transitions, vibrational structure and temperature dependence, J. 
Chem. Phys., 137, 054313, doi:10.1063/1.4739756, 2012c.

Solomon, S., Sanders, R. W., Garcia, R. R., and Keys, J. G.: Increased chlorine dioxide over Antarctica caused by volcanic aerosols from Mount Pinatubo, Nature, 363, 245-248, doi:10.1038/363245a0, 1993.

Solomon, S., Daniel, J. S., Neely, R. R., Vernier, J.-P., Dutton, E. G., and Thomason, L. W.: The persistently variable "background" stratospheric aerosol layer and global climate change, Science, 333, 866-870, doi:10.1126/science.1206027, 2011.

Suzuki, T., Katayanagi, H., Nanbu, S., and Aoyagi, M.: Nonadiabatic bending dissociation in 16 valence electron system OCS, J. Chem. Phys., 109, 5778-5794, doi:10.1063/1.477200, 1998.

Toyoda, S., Yoshida, N., Urabe, T., Aoki, S., Nakazawa, T., Sugawara, S., and Honda, H.: Fractionation of $\mathrm{N}_{2} \mathrm{O}$ isotopomers in the stratosphere, J. Geophys. Res., 106, 7515-7522, doi:10.1029/2000JD900680, 2001.

Turco, R. P., Whitten, R. C., Toon, O. B., Pollack, J. B., and Hamill, P.: OCS, stratospheric aerosols and climate, Nature, 283, 283-285, doi:10.1038/283283a0, 1980.

Ueno, Y., Johnson, M. S., Danielache, S. O., Eskebjerg, C., Pandey, A., and Yoshida, N.: Geological sulfur isotopes indicate elevated OCS in the Archean atmosphere, solving faint young sun paradox, P. Natl. Acad. Sci. USA, 106, 14784-14789, doi:10.1073/pnas.0903518106, 2009.
Watts, S. F.: The mass budgets of carbonyl sulfide, dimethyl sulfide, carbon disulfide and hydrogen sulfide, Atmos. Environ., 34, 761779, doi:10.1016/S1352-2310(99)00342-8, 2000.

Werner, H.-J. and Knowles, P. J.: A second order multiconfiguration SCF procedure with optimum convergence, J. Chem. Phys., 82, 5053-5063, doi:10.1063/1.448627, 1985.

Werner, H.-J. and Knowles, P. J.: An efficient internally contracted multiconfiguration-reference configuration interaction method, J. Chem. Phys., 89, 5803-5814, doi:10.1063/1.455556, 1988.

Yung, Y. L. and Miller, C. E.: Isotopic fractionation of stratospheric nitrous oxide, Science, 278, 1778-1780, doi:10.1126/science.278.5344.1778, 1997.

Zhao, Z., Stickel, R. E., and Wine, P. H.: Quantum yield for carbon monoxide production in the $248 \mathrm{~nm}$ photodissociation carbonyl sulfide (OCS), Geophys. Res. Lett., 22, 615-618, doi:10.1029/95GL00170, 1995.

Zuniga, J., Bastida, A., Alacid, M., and Requena, A.: Excited vibrational states and potential energy function for OCS determined using generalized internal coordinates, J. Chem. Phys., 113, 5695-5704, doi:10.1063/1.1290383, 2000. 